\title{
Entre a ciência e a diversão: análise comparativa de enunciados audiovisuais de divulgação científica e suas formas de diálogo com o público presumido
}

DOl: http://dx.doi.org/10.21165/el.v48i2.2250

\section{Beatriz Amorim de Azevedo e Silva'}

\section{Resumo}

Neste artigo, busca-se investigar como enunciados audiovisuais de divulgação científica circulando em meio digital manifestam o fundo aperceptível de compreensão responsiva de seu interlocutor presumido, isto é, as relações que este trava com diferentes esferas e gêneros, a partir das quais adquire preferências e inclinações dentro da cadeia discursiva mais ampla. Para tanto, utilizamos os conceitos do Círculo de Bakhtin unidos aos preceitos metodológicos da análise comparativa de discurso, que nos mostraram diferenças entre os dois canais que seriam causadas, por um lado, pela variação na cadeia discursiva a que o interlocutor presumido tem acesso e à qual toma uma posição, e por outro, pelas diferentes estratégias empregadas pelo sujeito-autor, visando à didatização e ao apelo publicitário de seu enunciado.

Palavras-chave: teoria bakhtiniana; análise comparativa de discursos; enunciado em meio digital; divulgação científica; interlocutor presumido.

1Universidade de São Paulo (USP), São Paulo, São Paulo, Brasil; beatriz.amorim.silva@usp.br; https://orcid.org/0000-0001-9472-3434 


\title{
Between science and fun: a comparative analysis of audiovisual utterances of scientific popularization and their ways of dialogue with the presumed interlocutor
}

\begin{abstract}
This article investigates the way on which audiovisual utterances of scientific popularization in the digital media manifest their presumed interlocutor's apperceptive background of responsive understanding. The latter represents the relations formed between the presumed interlocutor and different spheres and genres, from which it gathers preferences and inclinations inside a wider discursive chain. For this study, it was utilized the concepts of the Bakhtin Circle joined with the methodological precepts of the comparative analysis of discourse, that showed differences between the channels. These differences are supposedly caused by, one the one hand, the variation on the discursive chain to which the presumed interlocutor has access and takes a stand; and, on the other hand, the different strategies utilized by the subject-author on its utterance, aiming the didactization and the advertising appeal of the utterance itself.
\end{abstract}

Keywords: bakhtinian theory; comparative analysis of discourse; utterances in digital media; scientific popularization; presumed interlocutor.

\section{Introdução: o conceito de interlocutor presumido nas obras do Círculo de Bakhtin}

O presente artigo objetiva aprofundar as questões concernentes ao interlocutor presumido no enunciado, tal como entendido nas teorias do Círculo de Bakhtin, ao analisar, pelo viés da análise comparativa de discursos, a forma com que enunciados audiovisuais de divulgação científica (doravante DC) de diferentes línguas/culturas, circulando em meio digital (especificamente, no YouTube), inscrevem seu interlocutor presumido em diferentes elementos da construção do enunciado.

Ao falar de enunciados em meio digital, algumas singularidades se destacam. A primeira delas é a natureza recente do meio, caracterizado fortemente por sua efemeridade. A segunda é seu crescimento estrondoso, gerando um impacto crescente sobre o comportamento social generalizado e, consequentemente, sobre o comportamento discursivo, o que faz com que o meio digital seja um importante redefinidor das formas de produção e circulação de linguagem na atualidade, influenciando e modificando gêneros e modalidades de relação dialógica.

Essas alterações são feitas a partir da consideração de características particulares ao meio, tal como seu estilo de linguagem pautado pela informalidade (principalmente em enunciados voltados a um público jovem), sua disponibilidade de diversos meios de expressão material organizada (como, por exemplo, o meio audiovisual) e sua composição 
peculiar do interlocutor presumido, de caráter global, indefinido e indistinto, podendo abrigar concomitantemente um amplo e variado espectro social, isto é, um mesmo enunciado atinge muitas pessoas, as mais variadas possíveis, ao mesmo tempo. A DC em particular sofrerá uma remodelação que atingirá pontos chave de sua composição, dentre os quais a indeterminação do interlocutor presumido será central, uma vez que a DC depende em larga escala de seu público e terá, a partir de agora, de selecioná-lo em meio a uma massa pluralizada de públicos possíveis e chamá-lo para o enunciado, suscitando seu interesse. É sobre esta complexidade que nossa investigação irá se concentrar, especificamente.

Para tanto, começamos pela investigação sobre o conceito de interlocutor presumido, sobre o qual investigaremos três obras representativas para a discussão: "Os gêneros do discurso", de M. Bakhtin, O método formal nos estudos literários, de P. Medviédev, e Marxismo e Filosofia da Linguagem, de V. Volóchinov. A disposição de abordagem das obras justificase pelo caráter sintético da primeira que, por ter sido a última a ser escrita dentre as três, apresenta e aprofunda conceitos já elaborados anteriormente. Buscamos orientação na pesquisa de Higashi (2016) sobre o interlocutor inscrito em painéis expositivos de museus de ciência, na qual delimita os tópicos principais de cada autor sobre o assunto.

Em "Os gêneros do discurso" (BAKHTIN, 2011[1953-54]), o interlocutor é um dos elementos que definem o enunciado como tal. Isso porque o autor coloca como uma particularidade do enunciado o fato de que este não está em um paradigma abstrato e descontextualizado; é, ao contrário, uma unidade da comunicação discursiva, e é construído como tal. Assim, nele estaria já inserida a necessidade de uma resposta, uma vez que o diálogo não é constituído por enunciados lançados randomicamente, mas por reações subsequentes à fala anterior do outro sujeito. Portanto, um dos elementos constitutivos do enunciado é o apelo a uma atitude responsiva do interlocutor que o recebe.

Para que haja a construção desta teia comunicativa, Bakhtin (2011[1953-54]) confere ao interlocutor uma posição responsiva ativa dentro da comunicação; contudo, para além disso, o falante sabe dessa posição responsiva, espera-a e constrói seu enunciado de forma a provocá-la. Este direcionamento ao interlocutor determina o enunciado em todos os seus níveis de composição e leva em conta a constituição do interlocutor, sua relação com o falante, o contexto sociocultural em que ele se insere, e seu fundo aperceptível de compreensão responsiva, o qual é definido da seguinte forma:

Ao falar, sempre levo em conta o fundo aperceptível da percepção do meu discurso pelo destinatário: até que ponto ele está a par da situação, dispõe de conhecimentos especiais de um dado campo cultural da comunicação; levo em conta as suas concepções e convicções, os seus preconceitos (do meu ponto de vista), as suas simpatias e antipatias - tudo isso irá determinar a ativa compreensão 
responsiva do meu enunciado por ele. Essa consideração irá determinar também a escolha do gênero do enunciado e a escolha dos procedimentos composicionais e, por último, dos meios linguísticos, isto é, o estilo do enunciado. (BAKHTIN, 2011[1953-54], p. 302, grifo do autor).

Já em 0 método formal nos estudos literários, de Medviédev (2012[1928]), a importância do interlocutor é trazida por outro ângulo, por meio do que o autor denomina avaliação social:

Iremos chamar de avaliação social justamente essa atualidade histórica que reúne a presença singular de um enunciado com a abrangência e a plenitude do seu sentido, que individualiza e concretiza o sentido e compreende a presença sonora da palavra aqui e agora. Pois é essa avaliação social que atualiza o enunciado tanto no sentido da sua presença fatual quanto no do seu significado semântico. Ela determina a escolha do objeto, da palavra, da forma e a sua combinação individual nos limites do enunciado. Ela determina, ainda, a escolha do conteúdo e da forma, bem como a ligação entre eles. (MEDVIÉDEV, 2012[1928], p. 184).

Medviédev (2012[1928]) coloca, então, a questão da dualidade do enunciado, como realidade material, um processo físico - sons ocupando espaço na realidade física -, e como um acontecimento histórico, que ressoará nos próximos enunciados na cadeia discursiva e nos faz situar o enunciado como um ato social e inserido em uma comunicação concreta, tal como pensa Bakhtin. Além disso, o autor também ressalta a penetração da avaliação social em todas as camadas do enunciado, determinando-o completamente. É como se a avaliação social fosse o critério de escolha do que se quer plasmar na realidade histórica, e de que forma o fazer: "A avaliação social reúne a minuta da época e o assunto do dia com a tarefa da história. Ela determina a fisionomia histórica de cada texto e de cada enunciado, sua fisionomia de indivíduo de classe e época." (MEDVIÉDEV, 2012[1928], p. 185).

Por fim, em Marxismo e filosofia da linguagem, de Volóchinov (2017[1929]), o autor propõe que qualquer aspecto do enunciado está definido pelas suas próprias condições reais, as quais são determinadas inicialmente pela situação social imediata, uma vez que se formam "entre dois indivíduos socialmente organizados, e, na ausência de um interlocutor real, ele é ocupado, por assim dizer, pela imagem do representante médio daquele grupo social ao qual o falante pertence." (VOLÓCHINOV, 2017, p. 204). O autor, portanto, vincula diretamente o enunciado às suas condições de produção e, acima de tudo, à importância do interlocutor, para quem a palavra é orientada e que é uma parte essencial da constituição do enunciado, uma vez que, mesmo sem um interlocutor específico 
na situação social imediata, o locutor constrói uma imagem de interlocutor a partir do "horizonte social típico e estável para o qual se orienta a criação ideológica do grupo social e da época a que pertencemos [...]" (VOLÓCHINOV, 2017[1929], p. 205).

\section{0 interlocutor presumido nos enunciados de DC}

Menções à divulgação científica aparecem em dois momentos de "Os gêneros do discurso" (BAKTHIN, 2011[1953-54]), dos quais ressaltamos a passagem em que o autor fala sobre os gêneros científicos com interlocutor popular, no âmbito dos quais se insere a DC:

\footnotetext{
[...] os gêneros da literatura popular científica são endereçados a um determinado círculo de leitores dotados de um determinado fundo aperceptível de compreensão específica; a outro leitor está endereçada uma literatura didática especial e a outro, inteiramente diferente, trabalhos especiais de pesquisa. Em todos esses casos, a consideração do destinatário (e do seu fundo aperceptível) e a sua influência sobre a construção do enunciado são muito simples. Tudo se resume ao volume de seus conhecimentos especiais. (BAKHTIN, 2011[1953-54], p. 302, grifo meu).
}

Essa posição teórica encontra mais respaldo em algumas teorizações sobre a DC e menos em outras, de forma que podemos construir um espectro de enfoques investigativos sobre o processo de divulgação científica e a inscrição do fundo aperceptível de seu interlocutor presumido, em que caminhamos da simplificação deste no seu nível de conhecimentos, para a sua percepção em uma maior complexidade, levando em conta também sua posição social, ideológica e cultural, bem como os discursos com que têm contato ou não - é o caso das propostas de Grillo (2013), Cataldi (2007) e Roth e Scherer (2012), e a abordagem proposta por este artigo.

A exploração mais detida dessas diversas perspectivas, embora muito interessante, teve de ser resumida devido ao espaço e proposta principal a que se propõe o presente artigo. Elucidamos, porém, a posição que tomamos em nossa investigação, que se baseia na teoria do Círculo de Bakhtin e une aspectos de várias dessas pesquisas, de acordo com nosso objetivo: observar como a complexidade cultural-discursiva do interlocutor presumido está inserida na construção do enunciado de DC. Essa inserção seria realizada considerando que a DC se baseia no fundo aperceptível de compreensão responsiva do interlocutor presumido não somente como uma somatória de conhecimentos prévios sobre o assunto, mas incluindo também a relação deste interlocutor presumido com diversas esferas e gêneros, a partir da qual este adquire preferências e inclinações que moldam sua identidade dentro de uma cadeia discursiva mais ampla. 
Para tanto, adotaremos o conceito de DC de Grillo (2013), que considera a DC como uma modalidade de relação dialógica entre a esfera científica e outras esferas de atividade humana, incluindo-se a ideologia do cotidiano; um movimento de exteriorização da ciência para os estratos superiores da ideologia do cotidiano com a finalidade de criar no seu destinatário uma cultura científica, utilizando-se, para isso, da interação dialógica de várias outras esferas. Aqui, o autor divulgador não é um mediador apagado do discurso, e sim um construtor ativo, selecionando e produzindo a DC pela consideração do fundo aperceptível de compreensão responsiva de seu interlocutor presumido, o que dá o tom da orientação social da DC definida pela autora: a relatividade da distinção entre público leigo e especialista, o pressuposto da atitude responsiva ativa e o aumento dos conhecimentos.

Este conceito será aplicado tomando como referência Cataldi (2007) e Roth e Scherer (2012). Ambas as autoras também colocam a divulgação científica como um encontro de esferas diversas da atividade humana, ao mesmo tempo tentando estender a participação do interlocutor na construção do enunciado.

Roth e Scherer (2012), ao estudar a DC na mídia, evocam o que chamam de contrato de comunicação na mídia, o qual se dividiria em duas tendências mais ou menos conflitantes: o fazer saber, informar o público e fornecer-Ihe conhecimentos, por meio de estratégias de didatização; e o fazer sentir, cooptar o público para manter a audiência e popularidade do enunciado em seu meio, empregando estratégias de apelo publicitário.

Cataldi (2007, p. 156), por sua vez, focaliza o interlocutor presumido em sua complexidade cultural, uma vez que define a DC como "reformulação do conhecimento científico a partir das diversas variáveis (sociais, culturais, ideológicas, políticas, econômicas, espaçotemporais, entre outras) que condicionam a sua produção [...]". Essa seria produzida por um jornalista, que enfrentaria o problema de ter que aproximar o estilo científico ao estilo midiático, com um público amplo, heterogêneo, não especializado e cada vez mais interessado na esfera científica. Para tanto, o jornalista teria que destacar particularidades do mundo científico que respondam às necessidades cognitivas e sociais do público em geral, adequando-as aos meios de comunicação diversos e a suas funções sociais particulares.

\section{Metodologia de definição e análise do corpus}

Aliada a esses conceitos, será empregada a metodologia da análise de discursos comparativa, desenvolvida largamente pelos pesquisadores do grupo "Syled-Cediscor, axe sens et discours", e que tem como objetivo, de acordo com von Münchow (2004), o estudo da manifestação de um mesmo gênero discursivo em ao menos duas línguas/ culturas, buscando descrever e interpretar as regularidades discursivas. Dessa forma, sua utilização permite que comparemos enunciados que provêm de diferentes horizontes sociais generalizados e estão inscritos em situações sociais imediatas diversas. 
Seguindo esta proposta metodológica, devemos definir um tertium comparationis, isto é, a invariante principal que une os enunciados estudados e que permite sua comparação. Para nossa pesquisa, uma vez que tomamos os enunciados de DC a partir de Grillo (2013), estaremos alinhados a Silva Filho (no prelo) que, ao comparar diferentes enunciados de DC pelo viés bakhtiniano, utiliza como invariante principal a manifestação dessa modalidade de relação dialógica em enunciados de gêneros diferentes da esfera jornalística. Em nosso corpus, o tertium comparationis será, da mesma forma, a manifestação da DC nos enunciados orais de dois canais do YouTube, Nerdologia e Scishow, inscritos em línguas/ culturas diferentes, respectivamente Brasil e Estados Unidos. Adicionam-se, ainda, como invariantes secundárias, seu meio de circulação (o meio digital, especificamente o YouTube) e seu gênero discursivo - são vídeos de curiosidades científicas, enunciados audiovisuais com conteúdo temático voltado para aspectos da ciência que supostamente interessariam o público presumido, o qual é evocado de forma ostensiva durante o enunciado por meio da informalidade. A partir destes critérios, escolhemos dez vídeos, procurando manter um paralelo temático. A relação de vídeos encontra-se abaixo:

Quadro 1. Relação dos vídeos utilizados para compor nosso corpus, com exibição do seu título, sua data de upload no YouTube e o link para acesso

\begin{tabular}{|c|c|c|}
\hline TEMA & Vídeos do Nerdologia & Vídeos do Scishow \\
\hline Hipnose & $\begin{array}{l}\text { Hipnose | Nerdologia } 165 \\
01 / 09 / 16 \\
\text { https } / / \text { w ww.youtube.com/watch?v-a } \\
\text { 1sciIzdUF Y }\end{array}$ & $\begin{array}{l}\text { The Science of Hypnosis } \\
\text { 10/11/16 } \\
\text { https://www .youtube.com/watch?v-R } \\
\text { WMYNTnoEyQ }\end{array}$ \\
\hline $\begin{array}{l}\text { Matéria } \\
\text { Escura }\end{array}$ & $\begin{array}{l}\text { Os poderes da Lince Negra | } \\
\text { Nerdologia } 99 \\
17 / 09 / 15- \\
\text { https } / / \text { www.youtube.com/watch?v- } \\
\text { EkyRnJgHQhI }\end{array}$ & $\begin{array}{l}\text { Dark Matter } \\
27 / 12 / 12 \text { - } \\
\text { https } / / \text { www youtube com/watch?v=E } \\
\text { kyRnJgHQhI }\end{array}$ \\
\hline Mentiras & $\begin{array}{l}\text { O JEITINHO BRASILEIRO | } \\
\text { Nerdologia } 19 \\
13 / 02 / 14 \text { - } \\
\text { https } / / \text { www.youtube.com/watch?v= } \\
\mathrm{CM} 9 \times \mathrm{BBCj} 7 \mathrm{~h} 5 \mathrm{Q}\end{array}$ & $\begin{array}{l}\text { The Science of Lying } \\
01 / 07 / 12 \\
\text { https:/www youtube.com/watch?v-M } \\
\text { X3Hu } 810 X T E\end{array}$ \\
\hline $\begin{array}{l}\text { Zika } \\
\text { virus }\end{array}$ & $\begin{array}{l}\text { V imus Zika | Nerdologia } 112 \\
10 / 12 / 15 \\
\text { https } / / \text { www.youtube.com/watch?v= } \\
\text { pm3doOnEuuM }\end{array}$ & $\begin{array}{l}\text { Zika Virus: What We Know (And What } \\
\text { We Don't) } \\
05 / 02 / 16 \text { - } \\
\text { https } / / \text { www youtube com/watch?v=J } \\
\text { UlGN } 5 \text { X J } 5 \mathrm{dc}\end{array}$ \\
\hline Energia & $\begin{array}{l}\text { Energia | Nerdologia } 111 \\
03 / 12 / 15 \text { - } \\
\text { https } / / \text { w ww.youtube.com/watch?v=pXt } \\
\text { VUobPQLs }\end{array}$ & $\begin{array}{l}\text { World's Most A sked Questions: } \\
\text { What Is Energy? } \\
\text { 28/10/14 - } \\
\text { https://www youtube.com/watch?v-C } \\
\text { W0_S5Y pYVo }\end{array}$ \\
\hline
\end{tabular}

Fonte: Elaboração própria. 
Utilizamos os métodos de transcrição do NURC tal como apresentados por Castilho (2016), que nos permitem marcar com maior precisão os elementos de oralidade presentes nos enunciados. Adicionamos, ainda, realces em negrito nos exemplos transcritos para ressaltar os elementos que estão sendo discutidos.

Já na análise dos dados obtidos, baseamo-nos na metodologia empregada na análise comparativa de discursos, proposta por von Münchow (2004), a partir da qual definimos as categorias da linguagem analisadas, que se dividem em dois eixos de expressão material organizada: elementos da linguagem verbal, representados em nossa análise pela escolha lexical, e elementos da linguagem audiovisual, dos quais analisaremos a escolha de imagens/vídeos a serem exibidos durante a fala. Entretanto, devemos ressaltar que, uma vez que nossa análise se centra em enunciados de composição audiovisual (vídeos), estes dois eixos de análise são inalienáveis entre si, e serão analisados pela observação da forma como elementos dos dois eixos se unem na composição de um único sentido, o qual se associa ao recorte que o sujeito-autor busca fazer do tema geral proposto ao enunciado. Para entender melhor essa questão, analisaremos, antes de tudo, a escolha dos temas dos enunciados.

\section{Análise e interpretação do corpus}

\section{A escolha temática dos enunciados}

Por ser um corpus reduzido, temos apenas cinco temas com os quais trabalhamos (mentira, matéria negra, zika vírus, energia e hipnose, como no Quadro 1), que, no entanto, parecem refletir tendências gerais à escolha dos temas nos dois canais. Nosso corpus, por ser composto de vídeos de curiosidades científicas, possui um eixo temático bem definido: a divulgação de temas inerentes à esfera científica que supostamente interessam ao interlocutor presumido. Contudo, identificamos, dentro desse eixo geral, duas formas de seleção dos temas a serem abordados dentre toda a cadeia temática da esfera científica, as quais são: abordagem de temas científicos que remetem a elementos marcantes do cotidiano do interlocutor presumido e já possuem uma representação consolidada na ideologia do cotidiano como curiosidades gerais (no caso dos vídeos sobre mentira, hipnose e energia); e temas científicos largamente discutidos, de grande relevância na situação social e discursiva de produção dos enunciados (como seria o caso dos vídeos sobre o zika vírus e a matéria negra).

Esse processo de seleção de temas, comum a todo o corpus a nosso ver, não é materializado da mesma forma pelos dois canais: cada canal, ao selecionar um tema da grande cadeia temática da esfera científica, o faz de acordo com a avaliação social que possui daquele tema, isto é, de que forma o recorta do conjunto de temas gerais e o molda em seu enunciado, pautado pelos interesses que supõe em seu interlocutor presumido. 
Assim, um tema geral retirado da esfera científica, como, por exemplo, a matéria negra, é recortado pelo enunciado do Scishow de uma maneira (a partir de um panorama geral, ressaltando os mistérios da área e os desafios ainda remanescentes aos seus pesquisadores), e pelo enunciado do Nerdologia, de outra (aplicando o conceito geral à investigação dos motivos científicos por trás dos poderes de uma personagem dos quadrinhos). O interlocutor presumido, portanto, está manifesto nestes enunciados na forma da própria motivação dos recortes temáticos feitos por cada canal, bem como nos recursos utilizados para tratar do tema já selecionado, que, no caso do nosso corpus, são representados pela ação integrada dos elementos verbais e audiovisuais que serão analisados, cada qual com sua função, mas juntos construindo a tomada de posição daquele enunciado em relação ao tema a que se propõe falar, a partir do viés de interesse identificado em cada interlocutor presumido particularmente.

Observemos com mais cuidado como esse processo se dá concretamente na análise destes elementos, tanto no âmbito verbal, quanto no audiovisual.

\section{Meios de expressão material organizada: elementos verbais e audiovisuais, e suas particularidades}

Os dois eixos de expressão material organizada a que nos propomos analisar, conquanto interajam entre si na construção de sentidos, possuem comportamentos diferentes de acordo com a configuração do próprio meio digital, que lhes confere diferentes funções no enunciado. Entra aqui a questão da hipertextualidade, utilizada em Modolo (2012) para entender como funcionam os gêneros discursivos no meio digital a partir da pressuposição da leitura hipertextual por parte do interlocutor, pautada pelo acesso aos hiperlinks - ferramentas que levam o leitor de um enunciado a outros relacionados, e que influenciam significativamente a forma de recepção dos enunciados pelos interlocutores, bem como sua circulação no meio. Essa forma de leitura, ou de forma mais abrangente, de recepção dos enunciados, já seria pressuposta pelos gêneros digitais e estaria incorporada na estrutura textual:

\footnotetext{
Em nossa visão ampliada da hipertextualidade, podemos considerar que o hipertexto é mais do que links que rompem com a linearidade em determinados momentos da navegação na Internet, na verdade, a própria estrutura dos aparelhos informáticos e a maioria dos softwares já pressupõem um usuário que busque e compreenda sua forma hipertextual. Ao se deparar com um conjunto de pastas e arquivos disponíveis em um computador, não se imagina que o usuário deva ler ordenadamente e linearmente todos os arquivos e pastas nele presentes, na tentativa de buscar depreender algum sentido dos arquivos dispostos na tela do computador, pelo contrário, há uma leitura transversal e seletiva em que o usuário do computador
} 
procura e seleciona determinado programa, música, imagem ou texto armazenados na memória do computador, mudando e interagindo ao abrir e fechar os arquivos que o interessam. (MODOLO, 2012, p. 39-40).

Essas ponderações afetam nosso corpus no sentido de que a recepção dos enunciados audiovisuais que o compõem é feita pelo interlocutor de forma não linear, fazendo com que os elementos visuais do enunciado sejam, muitas vezes, ignorados em relação aos elementos orais, uma vez que o vídeo é apenas escutado enquanto se realiza outras tarefas, e não visto em sua integridade. A pressuposição desse tipo de leitura por parte do interlocutor no nosso corpus faz com que, em um vídeo de YouTube, tudo que se quer garantir que o interlocutor receba deva ser falado.

Temos, portanto, que os elementos orais se incumbem da introdução do conteúdo propriamente dito, bem como das referências que têm função importante na argumentação e exposição do conteúdo. Enquanto isso, os elementos visuais possuem função de corroborar, enriquecer e ilustrar o enunciado, reforçando o que está sendo dito por meio de tópicos que tematizam a fala do sujeito-autor, ou ilustrando-o por imagens, vídeos, diagramas, que deixem mais claro o tema central do enunciado, e por ventura até mesmo introduzam detalhes mais específicos e não essenciais sobre o assunto, visando ao interlocutor que se interesse e continue assistindo o vídeo, e não somente o ouvindo.

\section{Elementos verbais}

Inicialmente, observamos características que perpassam todas as utilizações de elementos verbais e as unificam: a manifestação da informalidade e a interação direta com o interlocutor. A informalidade, como anteriormente mencionado, é uma das características gerais do meio digital, principalmente no meio específico do YouTube, e é, portanto, justificada em sua aparição no corpus. A questão que se põe para nossa análise, então, é como essa informalidade se manifesta, que funções carrega no caso da DC e que sentidos veicula em relação ao interlocutor presumido.

No nível das escolhas lexicais, a informalidade aparece pelo uso de expressões características do cotidiano do interlocutor presumido (como se observa em (5), (6), (7) e (9), abaixo) - buscando aproximar-se de um diálogo informal e bem-humorado -, expressões idiomáticas (que aparecem em (3), por exemplo) e termos simplificados na explicação de conceitos científicos. Além disso, o sujeito-autor interage diretamente com o interlocutor em vários momentos da fala, pela proposição de práticas em conjunto e pela consideração da forma de pensar do interlocutor (propõe perguntas, curiosidades, enuncia o que ele deve estar pensando e vai respondendo ao longo da fala, passando por todo o processo da investigação científica - pergunta, resposta, problema, solução etc. e expõe testes e experimentos como exemplos). Nos exemplos, isso pode ser visto mais especificamente em (4), (5) e (10). 
A ocorrência destes elementos nos dois canais denota a tentativa de interagir com o interlocutor de forma direta e explícita, marcando uma proximidade entre este e o enunciado, almejando, por um lado, a suscitar seu interesse no assunto pela proximidade e relevância que este teria em sua vida - o que denota uma estratégia de apelo publicitário, como depreendemos de Roth e Scherer $(2012)^{2}$ - e, por outro, a facilitar sua compreensão dos conceitos divulgados - denotando, portanto, uma estratégia de didatização.

No entanto, estas estratégias empregadas pelo sujeito-autor são ancoradas no interlocutor presumido a que cada enunciado almeja, já que as expressões utilizadas devem ser próximas aos discursos que pertencem ao cotidiano do interlocutor, mas, mais precisamente, com os quais ele se identifica e adota para si, para que a linguagem do vídeo reflita seus usos linguísticos típicos. Dessa forma, no Nerdologia, a linguagem utilizada busca como interlocutor presumido o jovem identificado com a cultura nerd, que é caracterizada por familiaridade com alguns termos específicos à esfera científica (como em (1) e (2)) e pelo uso de termos característicos de nichos culturais específicos, como a ficção científica (como se vê em (2)), da seguinte forma:

1. LOC.1 - sejam bem vindos ao NERdologia ... eu sou átila biólogo PESquisador e fazendo BOM USO da minha energia ... [...] (Abertura, na qual o sujeito-autor se identifica com a esfera científica).

2. LOC.1 - [...] nos quadrinhos a kitty pryde ou LINce Negra tem o poder de ficar INTANGÍVEL ... e atravessar a matéria QUANDO quer ... [...] (Utilização de referências e termos característicos do nicho cultural conhecido pelo interlocutor, bem como termos técnicos científicos).

3. LOC.1 - [...] agora PENSE em QUANtos EXEMPLOS de trapaça reconhecida em rede NACIONAL nós temos ... SEM CONSEQUÊNCIAS ... só PIzza ... [...] (Utilização de expressão idiomática próxima ao cotidiano do interlocutor)

4. LOC. 1 - [...] conCENtre-se no relógio e perCEba sua respiração ... você tá ficando com SOno ... relaXAdo ... seus braços tão peSAdos ... e você sente uma vontade ENORME de compartilhar o nerdologia com seus amigos ... mas de onde veio isso? [...] (Exemplo de prática proposta em conjunto com o interlocutor, bem como integração da sua voz e do que ele deve estar pensando pela pergunta retórica)

20 que chamamos apelo publicitário refere-se ao que Roth e Scherer (2012) definem como elementos de aproximação entre ciência e sociedade na mídia, de modo a apelar à emoção do público receptor daquele enunciado e, dessa forma, cooptá-lo para o consumo da mídia específica, com vistas à manutenção da produtividade financeira. Algumas das estratégias citadas pelas autoras são: referências explícitas ao artigo científico, em conjunto com menções implícitas a discursos de conhecimento popular; uso de hiperlinks; e a indicação de posições enunciativas de diversos atores sociais, como o pesquisador e a comunidade científica, o governo, o público etc. 
5. LOC.1 - [...] AH ... mas isso foi entre estudantes ameriCAnos ... se repetissem o teste aqui COM CERTEZA haveria mais desonestidade ... será? ... pois repetiram o teste de matemática COM e SEM correção em diVERsos países do mundo ... o resultado? em todos eles as pessoas acertavam em média QUINze por cento a MAIS ... o que nos traz pra conclusão de dan ariely ... [...] (exemplo de integração da forma de pensar e da voz do interlocutor pela fala irônica e pela progressão da investigação científica, usando testes e experimentos como base)

O Scishow, por sua vez, utiliza elementos que se referem não só a nichos específicos de cultura, mas a elementos mais generalizados e conhecidos por um grupo maior de pessoas (como em (6)). Além disso, há menos termos científicos específicos, substituídos por versões simplificadas e mais próximas do cotidiano de seu interlocutor presumido jovem e indefinido (como em (8) e (9)). Assim, temos:

1. LOC. 1 - [...] you might've seen people fall asleep on command quack like a duck or even CHANGE persoNAlities ... like in the movie office space ... [...] (Utilização de termos informais e referências culturais generalizadas)

2. LOC.1 - [...] but he WASN'T just talking about SEX appeal ... [...] (Utilização de termos informais do cotidiano de um interlocutor generalizado)

3. LOC.1 - [...] well we can INFER its existence ... from things that we CAN detect ... like LIGHT and other forms of radiation ... plus all the things that they BOUNCE OFF OF ... and lets us SEE them... [...] (Utilização de termos simplificados para descrição de conceitos científicos)

4. LOC. 1 - [...] and unlike the flashy hypnotism you might see on TV ... CLInical hypnosis ... is pretty simple ... it's all about FOCUS ... [...] (simplificação do assunto e referência ao que o interlocutor conhece sobre o assunto)

5. LOC. 1 - hey yo ... time for TWO TRUTHS AND A LIE ... i'm gonna tell you three things about myself ... ahn ... and you gonna have to pick out the one ... that is NOT true ... ready? ok [...] (prática proposta em conjunto com o interlocutor)

\section{Elementos audiovisuais}

Como característica comum à utilização dos elementos audiovisuais pelos dois canais, temos a inscrição mais direta e explícita do interlocutor presumido e suas características próprias. Associamos essa tendência comum à já mencionada diferenciação de funções entre elementos verbais e visuais, em razão da pressuposição da leitura hipertextual; dessa forma, os elementos visuais destinam-se a um público ainda mais restrito do 
que os verbais, pois só serão efetivamente recebidos pela porção do público geral que assistir o vídeo integralmente, e não apenas ouvi-lo. Dentro desse contexto, a marcação do interlocutor presumido também é feita de modo mais especializado, específico e explícito, nos elementos visuais em comparação aos elementos verbais.

O fato de que, nos dois canais, vários elementos surgem em tela ao longo da fala expositiva já carrega uma característica dinâmica, cuja função principal é a de ilustrar e exemplificar o que está sendo dito, servindo à didatização do conteúdo, bem como interagir diretamente com o interlocutor presumido e o discurso com o qual se identifica ao trazer descontração e movimentação ao vídeo, as quais servem de apelo publicitário ao público jovem pela sua familiaridade com a leitura hipertextual, na qual a rapidez e fluidez na transmissão de informações são essenciais. Nos dois canais, os itens principais que aparecem são: tópicos tematizando a fala do sujeito-autor, citações parciais ou, em casos excepcionais, elementos não mencionados (consistindo em detalhes específicos e dispensáveis ao entendimento geral do assunto), imagens com legendas, animações, esquemas e gráficos. A variação entre os dois canais está na referência a que estes itens fazem, apelando às referências do próprio interlocutor presumido. Assim temos:

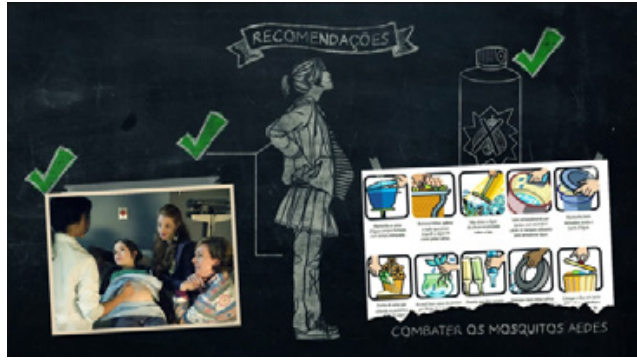

Imagem 1. Tópico tematizando o assunto, imagens e desenhos, símbolos padronizados

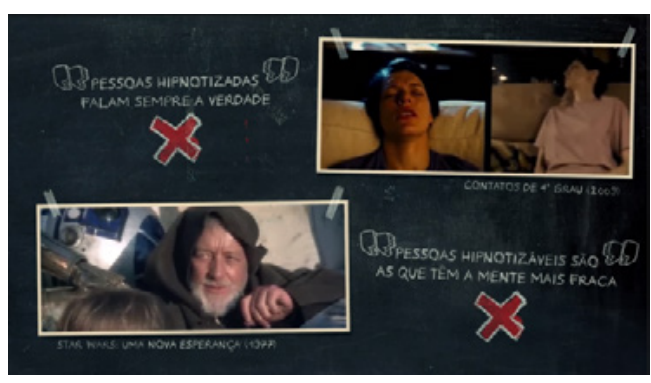

Imagem 3. Vídeos, citações parciais sobre o que está sendo dito, símbolos padronizados

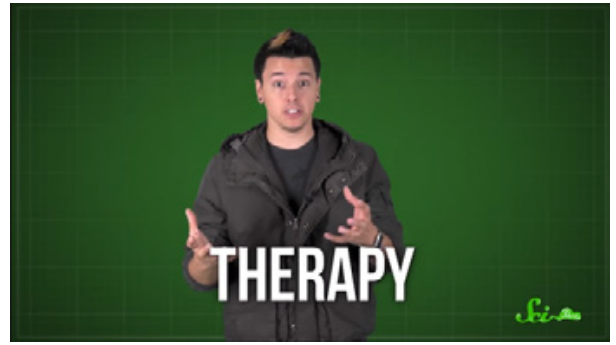

Imagem 2. Aparecimento do sujeito-autor, tópico tematizando o assunto

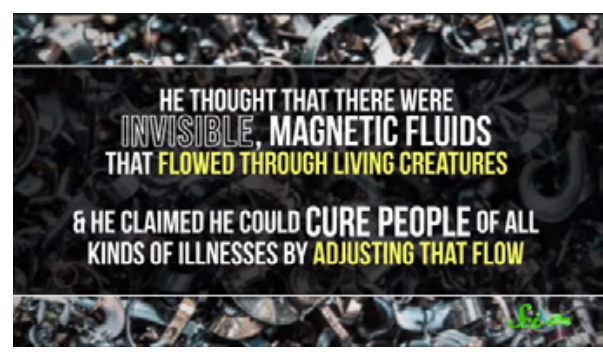

Imagem 4. Citação parcial sobre o que está sendo dito, imagem de fundo

Fonte: Nerdologia. 


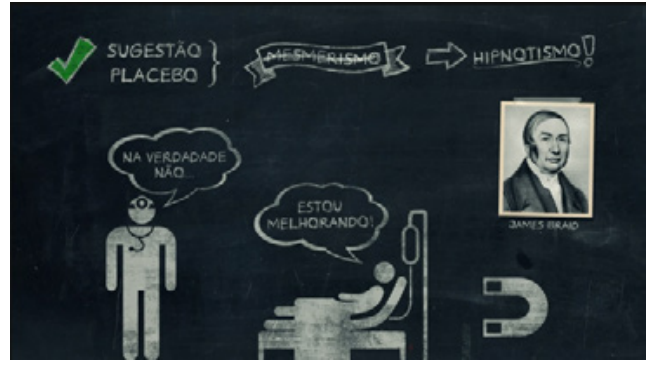

Imagem 5. Imagens, desenhos (compondo uma narrativa), tópico tematizando o assunto, símbolos padronizados

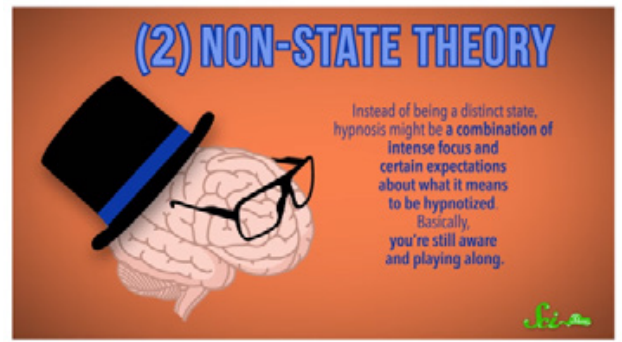

Imagem 6. Esquematização com tópico de assunto, explicação e desenho ilustrativo

Fonte: Scishow.

Os itens utilizados pelo Nerdologia fazem referência a um nicho mais específico de discursos relacionados ao entretenimento, como filmes e séries, geralmente associadas ao público nerd, identificado com estes discursos, como se pode ver principalmente nas imagens 1 e 3. No Scishow, por sua vez, as referências não são específicas, já que são utilizadas imagens generalizadas sobre o assunto tratado, o que marca um apelo a um interlocutor presumido não específico, como já identificado no canal, aparecendo com mais força na imagem 6.

Outra questão que se observa na comparação entre os canais é o fato de que, no Scishow, o sujeito-autor está constantemente presente em vídeo, enquanto no Nerdologia ocorre o contrário, toda a fala é feita sem que vejamos o sujeito-autor por trás dela. Este efeito gera diferentes sentidos: o Nerdologia, pelo não aparecimento do sujeito-autor no vídeo, produz um distanciamento com relação a seu interlocutor, aproximando-se da impessoalidade da posição de sujeito-autor da ciência; o Scishow, por sua vez, marca-se de forma mais próxima ao interlocutor, com uma didática mais explícita, afastando-se da impessoalidade característica do estilo científico para aproximar-se de um diálogo cotidiano informal entre interlocutor presumido e sujeito-autor (presente em vídeo). Portanto, encontramos o interlocutor presumido para o qual cada canal apela nestes elementos: o Nerdologia, voltado para o interlocutor nerd, familiarizado com elementos da cultura científica e, consequentemente, com seu estilo característico, e o Scishow, que busca o interlocutor generalizado, não necessariamente identificado com um discurso específico.

\section{Considerações finais}

A partir destas análises, podemos traçar o interlocutor presumido de ambos os canais e retirar destes dados algumas inferências gerais. O interlocutor presumido de ambos os canais tem como características gerais o pertencimento à fatia mais jovem da população, um bom esclarecimento e conhecimento dos fatos atuais que envolvam com mais ou 
menos intensidade temas científicos, bem como interesse e/ou curiosidade em aprender mais sobre estes assuntos.

Como diferenças, depreendemos que, no Scishow, o interlocutor presumido incitado pelo enunciado tem características mais generalizadas, não necessariamente possui um nível alto de conhecimentos sobre os assuntos, e sua identidade em relação às demais cadeias discursivas com que interage não é precisa e definida, o que se mostra na forma com que o canal toma os assuntos por um ângulo mais panorâmico, sem entrar em detalhes específicos sobre alguma questão, mas sim fornecendo conceitos básicos sobre o assunto e as movimentações atuais principais no campo de pesquisa.

Já o Nerdologia faz um recorte mais preciso de seus temas e, dessa forma, suscita um interlocutor presumido com uma identidade melhor definida - o público nerd, identificado com a cultura nerd, a qual, baseando-nos em Matos (2013), é caracterizada pela proximidade com relação à esfera científica e seus assuntos e gêneros típicos, bem como a discursos de outras esferas que ressoam os conhecimentos científicos, como a ficção científica e a fantasia medieval: "Nota-se que a cultura nerd, como se configura nos dias de hoje, é centrada no consumo de textos e artigos ligados à cultura pop que se mostra, então, como elemento fundamental da sociabilidade dos nerds e funciona como arena de disputas e trocas de capital simbólico e subcultural." (MATOS, 2013, p. 6).

Observa-se, portanto, como a questão do interlocutor presumido transpassa todos os níveis de construção do enunciado, como previsto pela teoria do Círculo, e não se resume somente ao seu nível de conhecimentos, mas, em vez disso, constrói-se como uma figura complexa e multifacetada, que toma posição em relação aos discursos a que tem acesso em sua língua/cultura específica. Notamos, ao mesmo tempo, a missão que se apresenta ao sujeito-autor do enunciado de DC de recortar esta complexidade, mantendo em mente a função social da DC disposta em Grillo (2013), e selecionar seu interlocutor a partir das lentes da didatização e do apelo publicitário, ao mesmo tempo em que adapta a construção de seu enunciado ao meio digital e a suas características peculiares.

\section{REFERÊNCIAS}

AUTHIER-REVUZ, J. A encenação da comunicação no discurso de divulgação científica. In: AUTHIER-REVUZ, J. Palavras incertas: as não-coincidências do dizer. Tradução E. P. Orlandi et al. Campinas: Ed. da UNICAMP, 1998 [1982]. p. 107-131.

BAKHTIN, M. Os gêneros do discurso. In: BAKHTIN, M. Estética da criação verbal. Tradução Paulo Bezerra. São Paulo: WMF Martins Fontes, 2011. p. 261-306.

CASTILHO, A. T. A conversação e o texto. Gramática do português brasileiro. São Paulo: Contexto, 2016. p. 225-238. 
CATALDI, C. A divulgação da ciência na mídia impressa: um enfoque discursivo. In: GOMES, M. C. A.; MELO, M. S.de S.; CATALDI, C. (org.). Gênero discursivo, mídia e identidade. Viçosa: Ed. UFV, 2007. p. 155-164.

DARK Matter. [s.I]: Scishow, 2012. Son., color. Disponível em: https://youtu.be/VL6ZNHiqP9A. Acesso em: 09 dez. 2017.

ENERGIA | Nerdologia 111. [s.I.]: Nerdologia, 2015. Son., color. Disponível em: https://youtu.be/pXtVUobPQLs. Acesso em: 09 dez. 2017.

GRILLO, S. V. C. Divulgação científica: linguagens, esferas e gêneros. 2013. Tese (Livredocência em Filologia e Língua Portuguesa) - Faculdade de Filosofia, Letras e Ciências Humanas, Universidade de São Paulo, São Paulo, 2013.

HIGASHI, A. O destinatário inscrito na exposição Alertas, do museu Catavento Cultural. Estudos Linguísticos, São Paulo, [s.I.], v. 45, n. 3, p. 717-732, 29 nov. 2016. Disponível em: https://revistas.gel.org.br/estudos-linguisticos/article/view/750. Acesso em: 02 abr. 2018.

HIPNOSE | Nerdologia 165. [s.l.]: Nerdologia, 2016. Son., color. Disponível em: https://youtu.be/alscilzdUFY. Acesso em: 09 dez. 2017.

MEDVIÉDEV, P. O método formal nos estudos literários: introdução crítica a uma poética sociológica. São Paulo: Contexto, 2012. p. 165-207. Tradução Sheila Camargo Grillo e Ekaterina Vólkova Américo.

MODOLO, A. D. R. Hipertextualidade e relações dialógicas no gênero digital microblog político dos candidatos à presidência do Brasil nas eleições 2010. 2012. Dissertação (Mestrado em Letras) - Faculdade de Filosofia, Letras e Ciências Humanas, Universidade de São Paulo, São Paulo, 2012. Disponível em: http://www.teses.usp.br/teses/disponiveis/8/8142/tde11042013-125748/pt-br.php. Acesso em: 07 jun. 2018.

MATOS, P. Consumo, curadoria e a construção de mapas de importância na cultura nerd. In: POSCOM - SEMINÁRIO DOS ALUNOS DE PÓS-GRADUAÇÃO EM COMUNICAÇÃO SOCIAL DA PUC-RIO, 10., 2013, Rio de Janeiro. Comunicação. Rio de Janeiro: Poscom Seminário dos Alunos de Pós-graduação em Comunicação Social da PUC-Rio, 2013.

MOIRAND, S. Formas discursivas da difusão de saberes na mídia. Rua, Campinas, n. 6, p. 9-24, 2000. 
O JEITINHO BRASILEIRO | Nerdologia 19. [s.I.]: Nerdologia, 2014. Son., color. Disponível em: https://youtu.be/CM9xBCj7h5Q. Acesso em: 09 dez. 2017.

OS PODERES da Lince Negra | Nerdologia 99. [s.I.]: Nerdologia, 2015. Son., color. Disponível em: https://youtu.be/EkyRnJgHQhl. Acesso em: 09 dez. 2017.

ROTH, D. M.; SCHERER, A. S. EXPANSÃO E CONTRAÇÃO DIALÓGICA NA MÍDIA: INTERTEXTUALIDADE ENTRE CIÊNCIA, EDUCAÇÃO E JORNALISMO. DELTA: Documentação e Estudos em Linguística Teórica e Aplicada, [S.I.], v. 28, n. 3, p. 639-672, dez. 2012. Disponível em: https://revistas.pucsp.br/index.php/delta/article/view/19373. Acesso em: 02 abr. 2018.

SILVA FILHO, U. C. da. Traços de didaticidade na divulgação científica brasileira e francesa: uma análise dialógico-comparativa do discurso de Ciência Hoje e La Recherche. In: I COLÓQUIO BRASILEIRO-FRANCO-RUSSO EM ANÁLISE DE DISCURSO (CBFR-AD), 1. , 2017, São Paulo. (a publicar)

THE Science of Hypnosis. [s.I.]: Scishow, 2016. Son., color. Legendado. Disponível em: https://youtu.be/RWMYNTnoEyQ. Acesso em: 09 dez. 2017.

THE Science of Lying. [s.l.]: Scishow, 2012. Son., color. Disponível em: https://youtu.be/MX3Hu8loXTE. Acesso em: 09 dez. 2017.

VÍRUS Zika | Nerdologia 112. [s.l.]: Nerdologia, 2015. Son., color. Disponível em: https://youtu.be/pm3do0nEuuM. Acesso em: 09 dez. 2017.

VOLÓCHINOV, V. N. Marxismo e filosofia da linguagem. Problemas fundamentais do método sociológico na ciência da linguagem. Tradução S. Grillo e E. V. Américo. São Paulo: Ed34, 2017[1929].

VON MÜNCHOW, P. Réflexions sur une linguistique de discours comparative: le cas du journal télévisé en France et en Allemagne. Tranel, Neuchâtel, p. 47-70. jun. 2004. Disponível em: http://www.unine.ch/cms/render/live/en/sites/tranel/home/tous-lesnumeros/tranel-40.html. Acesso em: 22 set. 2017.

WORLD'S Most Asked Questions: What Is Energy? [s.I.]: Scishow, 2014. Son., color. Disponível em: https://youtu.be/CW0_S5YpYVo. Acesso em: 09 dez. 2017.

ZIKA Virus: What We Know (And What We Don't). 2016. Son., color. Disponível em: https://youtu.be/JUIGN5XJ5dc. Acesso em: 09 dez. 2017. 